\title{
PROPOSTA PARA DETERMINAÇÃO DE EVENTOS EXTREMOS DE CHUVA NO LITORAL NORTE PAULISTA
}

\author{
SANTOS, Denise Dias dos - denise.dias.santos@usp.br \\ Universidade de São Paulo - USP \\ GALVANI, Emerson - egalvani@usp.br \\ Universidade de São Paulo - USP
}

\begin{abstract}
RESUMO: O Litoral Norte Paulista é, historicamente, marcado por eventos de precipitação extremas e características de relevo e solos que propiciam o desenvolvimento de desastres naturais como escorregamentos, inundações, entre outros. O objetivo deste estudo é realizar a análise dos eventos extremos de precipitação em uma feição climática definida por Monteiro (1973), com o uso da técnica estatística do Box Plot. Os resultados apresentados demonstram que os eventos extremos são aqueles que ultrapassam os valores de $99 \%$ do conjunto de dados e assim, definiram-se os limiares de evento extremo para cada posto. Os eventos extremos apresentaram sazonalidade, concentrados na estação mais chuvosa (verão e primavera), corroborando com os resultados encontrados na literatura para a área de estudo. $\mathrm{Na}$ análise comparativa dos três postos pluviométricos, o posto E2-046 obteve o maior número de registros de eventos extremos, porém o posto E2-009 apresentou o maior valor extremo de $500,0 \mathrm{~mm}$ em 24 horas. Este resultado pode ser explicado pela localização do posto na escarpa da Serra do Mar, que influencia o volume de precipitações ocorridas nesta localidade. A compreensão da ocorrência dos eventos extremos é relevante para o planejamento de ações que permitam a previsão e prevenção das consequências dos desastres naturais na área de estudo. A pesquisa também aponta a importância da padronização do sistema de análise de eventos extremos para auxiliar nos estudos da relação entre precipitações e desastres no Litoral Norte Paulista.
\end{abstract}

Palavras-Chave: Precipitação, eventos extremos, Box Plot.

\section{PROPOSAL FOR DETERMINATION OF EXTREME RAINFALL EVENTS IN THE NORTH} COASTLINE OF SÃO PAULO

ABSTRACT: The State of São Paulo's North Coastline has historically been marked by extremes rainfall events and features of relief and soil promote the development of natural disasters such as landslides, floods, among others. The purpose of this study is to perform an analysis about the events extremes rainfall in a climatic feature defined by Monteiro (1973), using the statistical technique of Box Plot. The results presenter shows that the Box Plot graphics had defined the extreme events are those that exceed values above $99 \%$ of the data set and thus, the extreme event thresholds for each defined station. The extreme events presented seasonality, concentrated in the most rainy season (summer and spring), corroborating with the results found in the literature for the study area. In the comparative analysis of the three rain gauges, station E2-046 obtained the highest number of records of extreme events, but on the E2-009 station it was presented the highest extreme value of $500.0 \mathrm{~mm}$ in 24 hours. This result is explained by the location of the rain gauge on the escarpment of Serra do Mar, which influences the volume of rainfall occurred in this locality. The understanding of the occurrence of extreme events is relevant in order to planning of actions that allow the prediction and prevention of the consequences of natural disasters in the study area. The research also points out the importance of the standardization of the system of analysis of extreme events to assist in the studies of the connection between rainfall and disasters in the North Coastline of São Paulo.

Keywords: Rainfall, extreme events, Box Plot.

PROPUESTA PARA LA DETERMINACIÓN DE EVENTOS EXTREMOS DE LLUVIA EN LITORAL NORTE PAULISTA 
RESUMEN: El Litoral Norte Paulista es, históricamente, marcado por eventos de precipitación extremos y características de relieve y suelos que propician el desarrollo de desastres naturales cómo deslizamientos, inundaciones, entre otros. El objetivo de este estudio es realizar el análisis de los eventos extremos de precipitación en un rasgo climático definido por Monteiro (1973), con el uso de la técnica estadística del Box Plot. Los resultados presentados demuestran que los eventos extremos son aquellos que superan los valores del $99 \%$ del conjunto de datos y así, se definieron los umbrales de evento extremo para cada puesto. Los eventos extremos presentaron estacionalidad, concentrados en la estación más lluviosa (verano y primavera), corroborando con los resultados encontrados en la literatura para el área de estudio. En el análisis comparativo de los tres puestos pluviométricos, el puesto E2-046 obtuvo el mayor número de registros de eventos extremos, pero el puesto E2-009 presentó el mayor valor extremo de $500,0 \mathrm{~mm}$ en 24 horas. Este resultado puede ser explicado por la ubicación del puesto en la escarpa en la Serra do Mar, que influye en el volumen de precipitaciones ocurridas en esta localidad. La comprensión del ocurrencia de los eventos extremos es relevante para la planificación de acciones que permitan la previsión y prevención de las consecuencias de los desastres naturales en el área de estudio. La investigación también apunta la importancia de la estandarización del sistema de análisis de eventos extremos para auxiliar en los estudios de la relación entre precipitaciones y desastres en el Litoral Norte Paulista.

Palabras Clave: Precipitación, eventos extremos, Box Plot.

\section{INTRODUÇÃO}

O Litoral Norte Paulista (LNP) tem importância turística para o Estado de São Paulo e pertence ao domínio dos mares de morros, sendo o "meio físico, ecológico e paisagístico mais complexo e difícil do país em relação às ações antrópicas" e "trata-se, ainda, da região sujeita aos mais fortes processos de erosão e de movimentos coletivos de solos em todo território brasileiro (faixa Serra do Mar e bacia do Paraíba do Sul)" (AB'SÁBER, 2003, p.17). A presença da Serra do Mar influencia a chegada e o deslocamento de sistemas atmosféricos comuns do clima transicional da região.

Atualmente, a localidade se destaca pelo crescente desenvolvimento urbano, como as obras do novo Porto de São Sebastião, o Gasoduto Caraguatatuba-Taubaté e a duplicação da Rodovia dos Tamoios (trechos de planalto e de serra), que atraem investimentos em infraestrutura comercial e turística, bem como o deslocamento de novos moradores e visitantes para áreas que antes não eram povoadas e/ou ocupadas. Ao estudar a percepção climática de trabalhadores do ramo da pesca no município de Caraguatatuba, Seixas (2014) afirma que as instabilidades atmosféricas provocam "ressacas" no mar; em conjunto, a mudança na direção dos ventos provocam alterações nas correntes marinhas e prejudicam a pesca. Para os trabalhadores, o maior desafio é a previsão das condições de tempo em curto prazo, de modo a proporcionar menores impactos quando há a ocorrência de eventos extremos que provocam estas alterações atmosféricas e marítimas.

O estudo dos eventos extremos de chuva também é importante para previsão e prevenção de desastres naturais. Porém, para cada região deve-se avaliar qual metodologia é adequada para a definição do evento extremo. Inserido no debate sobre a definição do que são os eventos extremos, existe também o interesse em avaliar seus impactos sobre a sociedade, principalmente no meio urbano. Para Armond e Sant'anna Neto (2017), é necessário reconhecer a diferenciação entre o que é um evento extremo de chuva, 
caracterizado pela sua origem estatística (que está fora do padrão climatológico para determinada área) e o que é um episódio extremo, designado como de natureza geográfica, pois envolve a produção desigual do espaço que sofre com os impactos causados pelos eventos (alagamentos, inundações deslizamentos, entre outros). Este estudo se preocupará apenas com a ocorrência de eventos extremos, dada a natureza das séries históricas aqui trabalhadas.

O objetivo deste trabalho é, com o uso da técnica de Box Plot, definir o limiar de ocorrência dos eventos extremos de chuva para cada posto pluviométrico e realizar uma comparação dos registros de eventos extremos.

\section{MATERIAIS E MÉTODOS}

\section{1 ÁREA DE ESTUDO}

De acordo com Silva (1975), os geógrafos brasileiros iniciaram os estudos sobre o litoral do Estado de São Paulo a partir da década de 1940, sendo João Dias da Silveira o pioneiro na área. França (1951) estudou a Ilha de São Sebastião "com amplas e minuciosas considerações a respeito do Litoral Norte" (SILVA, 1975, p.8). Posteriormente, na área da Geomorfologia, merece destaque Cruz (1974), que estudou a Serra do Mar e o litoral na região de Caraguatatuba, principalmente com contribuições acerca dos desastres naturais ocorridos em março de 1967. Na Climatologia, uma das obras de grande relevância é de Conti (1975), que desenvolveu um trabalho detalhado sobre a gênese das chuvas na porção lesnordeste do Estado de São Paulo, com ênfase à circulação secundária e ao efeito orográfico na parcela litorânea da sua área de estudo.

Galvani e Lima (2012) realizaram uma revisão bibliográfica acerca dos autores que trabalharam com o objetivo de classificar e regionalizar as precipitações no estado de São Paulo. Os estudos consideraram diversos aspectos como hidrografia, paisagens geográficas, regiões ecológicas, corespondência entre precipitação e relevo, e gênese das precipitações (OLIVEIRA, 1928; SCHROEDER, 1956; SETZER, 1966; BLANCO; GODOY, 1967; MONTEIRO, 1973; DAEE, 1972 e 1990; SANT'ANNA NETO, 1995). Para este trabalho, foi eleita a classificação de Monteiro (1973), pois a mesma realiza um recorte na área de estudo que é adequada para a escala da pesquisa proposta. A escolha por trabalhar com as feições climáticas deu-se pela necessidade de estabelecer uma área de estudo com cobertura de postos pluviométricos que possuísse longas séries históricas de dados produzidos em escala diária. A região possui valor científico climático e geomorfológico, visto que o relevo cumpre o papel de influenciar os tipos de tempo atuantes na região.

A figura 1 ilustra a localização da área de estudo, que possui 1.321,150 $\mathrm{km}^{2}$. Está inserida no Litoral Norte do estado de São Paulo, pertencente à Região Metropolitana do Vale do Paraíba e Litoral Norte - RMVPLN (EMPLASA, 2016). O LNP faz divisa com o município de Cunha e o estado do Rio de Janeiro ao norte, o Oceano Atlântico a leste e ao sul, Bertioga e Salesópolis a oeste, Paraibuna, Natividade da Serra e São Luis do Paraitinga a noroeste, com área total de $1.941,836 \mathrm{~km}^{2}$ e uma população total de 323.991 habitantes.

A unidade paisagística da Serra do Mar, presente na área de estudo, é revestida pela vegetação de Mata Tropical Atlântica (atualmente renomeada de Floresta Ombrófila Densa), reflexo do clima quente e úmido da região, reforçada 
pela umidade do oceano, integrando o Domínio de Mares de Morros, na classificação de AB'Sáber (TITARELLI, 1986). Parte desta vegetação faz parte do Parque Estadual da Serra do Mar (PESM). Na área de estudo estão presentes dois núcleos do PESM: Caraguatatuba e Picinguaba. A criação do parque estadual foi um marco na história da preservação da mata atlântica na região. Jequitibás (Cariniana estrellensis), canelas (Cinnamomum zeylanicum), cedros (Cedrela fissilis), jatobás (Hymenaea courbaril), ipês (gênero Tabebuia e suas variações), guapuruvus (Schizolobium parahyba) e manacás-da-serra (Tibouchina mutabilis) são algumas das espécies da flora que caracterizam a riqueza da floresta perene úmida de encosta, um sinônimo de mata atlântica. 0 parque abriga e mantém inúmeras nascentes que formam os riachos e córregos que fazem parte de importantes bacias hidrográficas, como as dos rios Pardo, Guaxinduba e Claro. O local é aberto para visitação, possui trilhas que podem ser percorridas com guias e cachoeiras.
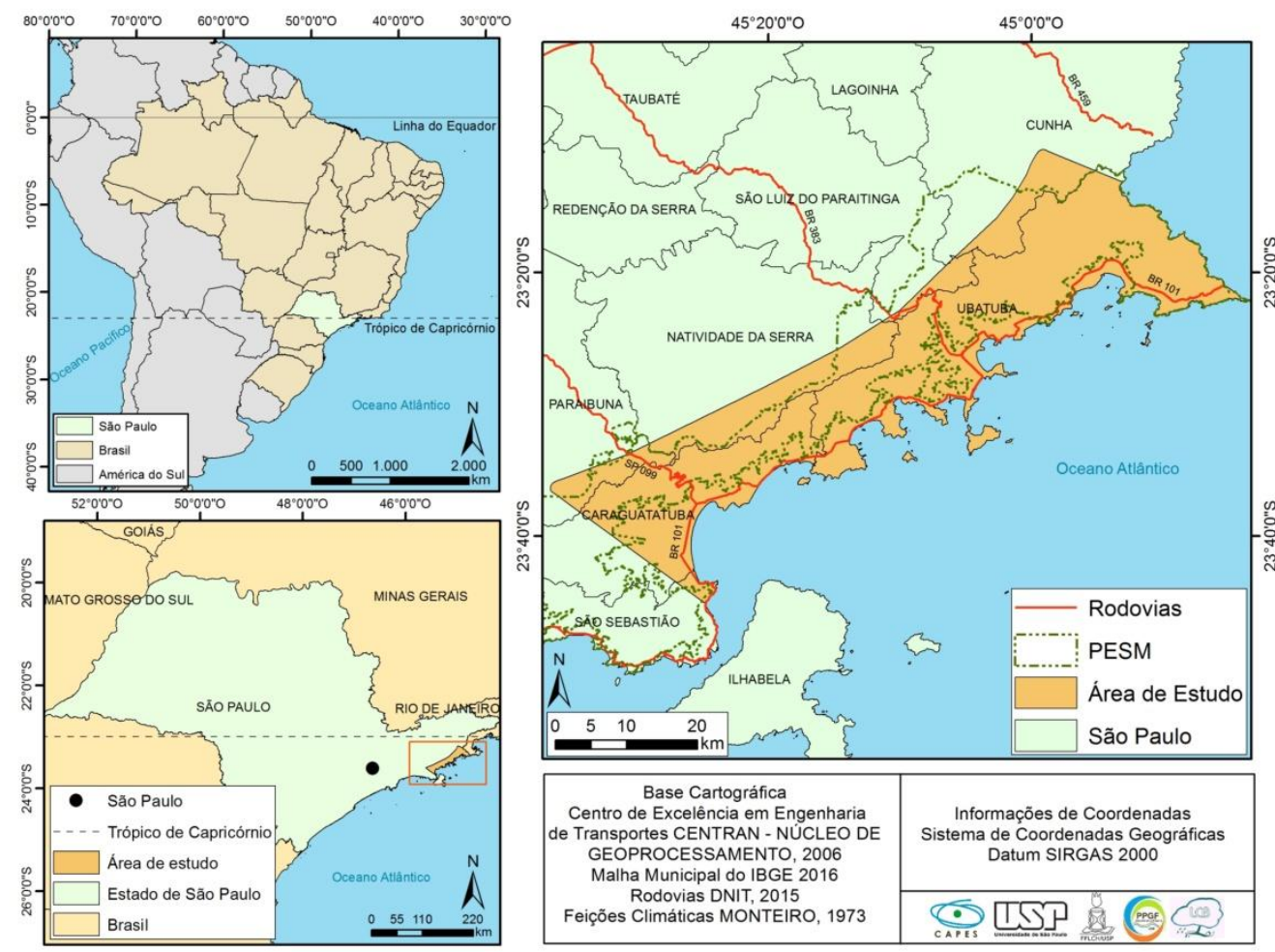

Figura 1 - Localização da área de estudo.

Ao estudar os climas do estado de São Paulo, Setzer (1946) afirma que a variedade de tipos climáticos na região está presente porque a mesma, em primeiro lugar, está em uma área de transição de climas tropicais para subtropicais. Em segundo lugar, "as variações de altitudes de tipos fisiográficos (...) condicionam diferenças de temperatura e retém pelas suas serras, ou afugenta pelos seus vales superaquecidos, as chuvas que caminham segundo direções prediletas." (p.35).

Silva et al. (2005) destacam que no LNP não há uma estação seca definida; durante a primavera e o verão, os totais pluviométricos podem ultrapassar os 2000 mm, no inverno e outono esse valor fica próximo aos 500 
mm, comprovando que há somente uma diminuição nos totais de precipitação durante estas estações. Como exemplo, a figura 2 apresenta o climograma para - município de Ubatuba e a tabela 1 expõe os dados climatológicos dos municípios na qual a área de estudo está inserida, de acordo com a classificação de Köppen. Estes resultados coincidem com os encontrados por Alvarez et al. (2013), onde o clima do tipo Af foi mapeado em quase todo litoral do estado de São Paulo, nas áreas de planícies costeiras com altitudes inferiores a 150 metros, sendo a localidade de maior altitude onde este tipo de clima ocorre na América do Sul.

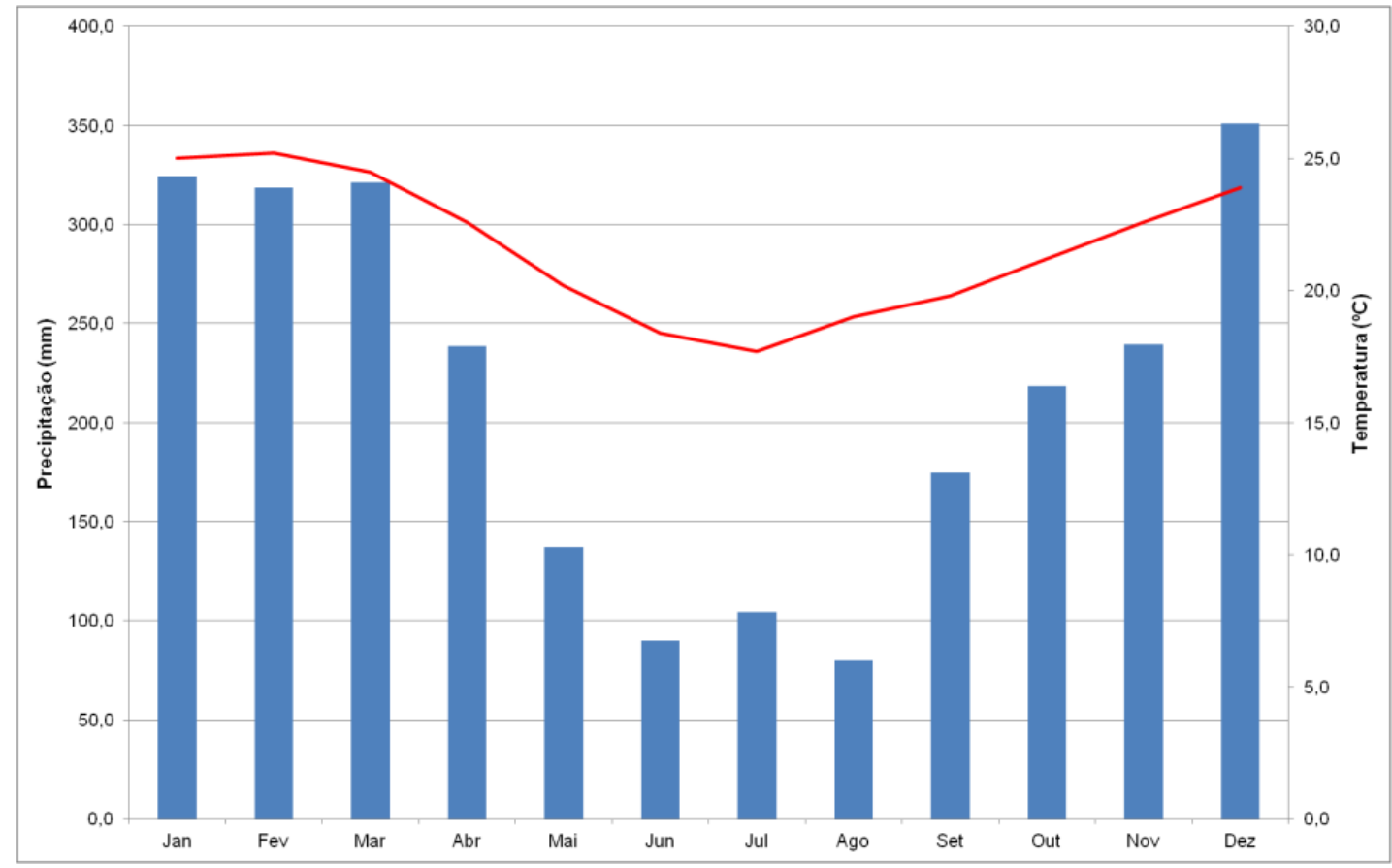

Figura 2 - Climograma para o município de Ubatuba (Normal Climatológica 1961-1990). Fonte: INMET.

Tabela 1 - Classificação climática de Köppen para os municípios do Litoral Norte Paulista. Fonte: CEPAGRI.

\begin{tabular}{ccccc}
\hline Município & $\begin{array}{c}\mathbf{T}_{\text {max média }} \\
\left({ }^{\circ} \mathbf{C}\right)\end{array}$ & $\begin{array}{c}\mathbf{T}_{\text {min média }} \\
\left({ }^{\circ} \mathbf{C}\right)\end{array}$ & $\begin{array}{c}\text { Precipitação média } \\
\text { anual }(\mathbf{m m})\end{array}$ & $\begin{array}{c}\text { Classificação } \\
\text { Köppen }\end{array}$ \\
\hline Caraguatatuba & 31,6 & 18,2 & 1757,9 & Af \\
\hline Ubatuba & 27,3 & 17,8 & 2154,2 & Af \\
\hline
\end{tabular}

A presença da Serra do Mar é de extrema importância para a compreensão da climatologia do LNP. Ela é responsável pelo desenvolvimento das precipitações orográficas e pelo deslocamento de sistemas atmosféricos que chegam à região. Nas vertentes da Serra do Mar, o efeito orográfico provoca acentuado aumento da pluviosidade, superando $3000 \mathrm{~mm}$, além de se posicionarem em direção conflitante às correntes atmosféricas de sul e sudeste (MILANESI, 2007; PELEGATTI, 2007). Diferentemente da configuração do Litoral Sul, ao norte a Serra do Mar se faz presente muito próxima ao litoral. A exceção 
é o "bolsão formado pela enseada de Caraguatatuba, que se assemelha a um imenso anfiteatro e chega a atingir cerca de $10 \mathrm{~km}$ de largura" (SANT'ANNA NETO, 1990, p.19). Esta estrutura de relevo proporciona a formação do efeito de chuva orográfica e influencia na penetração da Frente Polar Atlântica (FPA) no município. Devido à latitude, o clima é influenciado pelas massas tropicais, com chuvas intensas durante o verão e sem estação seca, mesmo durante o inverno.

Além da importância do relevo, o oceano também atua como controle do clima. Além de fornecer umidade que propicia a formação das nuvens, que se deslocam para a serra e forma a precipitação orográfica, o Oceano Atlântico é responsável na formação de sistema atmosféricos atuantes na região. Ao realizar um resgate de estudos sobre a variabilidade climática, Silva e Silva (2012) demonstram a importância de se correlacionar os processos que acontecem na atmosfera e nos oceanos para a compreensão das variáveis do clima, suas frequências e seus extremos. A alta capacidade térmica da água e os processos físicos que ocorrem na atmosfera podem ser associados à variabilidade climática e aspectos dos oceanos. A temperatura da superfície do mar (TSM) também é atributo que age na concepção e deslocamento dos sistemas, podendo ser caracterizada como um agende modelador do clima (SILVA; SILVA, 2012).

O Sudeste brasileiro é uma área de transição de climas. Esta configuração afeta o sistema regular e de previsão das condições de tempo de curto a longo prazo na região (SANT'ANNA NETO, 2005). Esta característica também é notável na zona costeira do Estado de São Paulo. Durante o verão há a atuação das correntes de leste (resultante dos alíseos) trazidas pela mTa, que produzem a condição de tempo estável. Ao encontrar a Serra do Mar (à barlavento), se eleva produzindo um aumento de umidade e precipitação; ao descer (à sotavento), pelo efeito adiabático, há a diminuição (ressecamento) da umidade e aumento da temperatura do ar.

Em relação às correntes de sul, a entrada do anticiclone polar atlântico produz extensas áreas de instabilidade atmosférica frontal, ao entrar em contato com as massas tropicais. O conjunto da atuação dessas correntes com a umidade fornecida pelo oceano provocam as chuvas de primavera e verão. Durante o inverno, as massas tropicais mais frágeis são empurradas pelo anticiclone, que avança para as latitudes mais baixas, proporcionando a evolução da massa polar. A ZCAS é responsável pelas perturbações frontais durante sua atuação no Sudeste, refletindo seus efeitos na área de estudo. Também atuam as linhas de instabilidade tropical (quando se encontram o ar úmido do oceano com o ar seco do continente) (SANT'ANNA NETO, 2005). Aliada à atuação da ZCAS, há também a Zona de Convergência de Umidade (ZCOU), que possui aspectos similares ao primeiro sistema. A ZCOU se diferencia por atuar apenas por três dias consecutivos, ou então quando se inicia a dissipação de uma ZCAS (SACRAMENTO NETO et al., 2010).

\subsection{SELEÇÃO E ORGANIZAÇÃO DO BANCO DE DADOS}

Para esta pesquisa foram selecionados dados secundários de três postos pluviométricos na área de estudo: um pertencente ao município de Caraguatatuba e dois vinculados ao município de Ubatuba, fornecidos pelo Departamento de Águas e Energia Elétrica do estado de São Paulo (DAEE), por 
meio de sua plataforma online de dados pluviométricos e hidrológicos do estado de São Paulo. Para seleção de eventos extremos foram selecionados os postos de acordo com sua localização geográfica (altitude em relação ao nível do mar e representação espacial no contexto da área de estudo). A figura 3 e a tabela 2 apresentam a localização de cada posto pluviométrico.

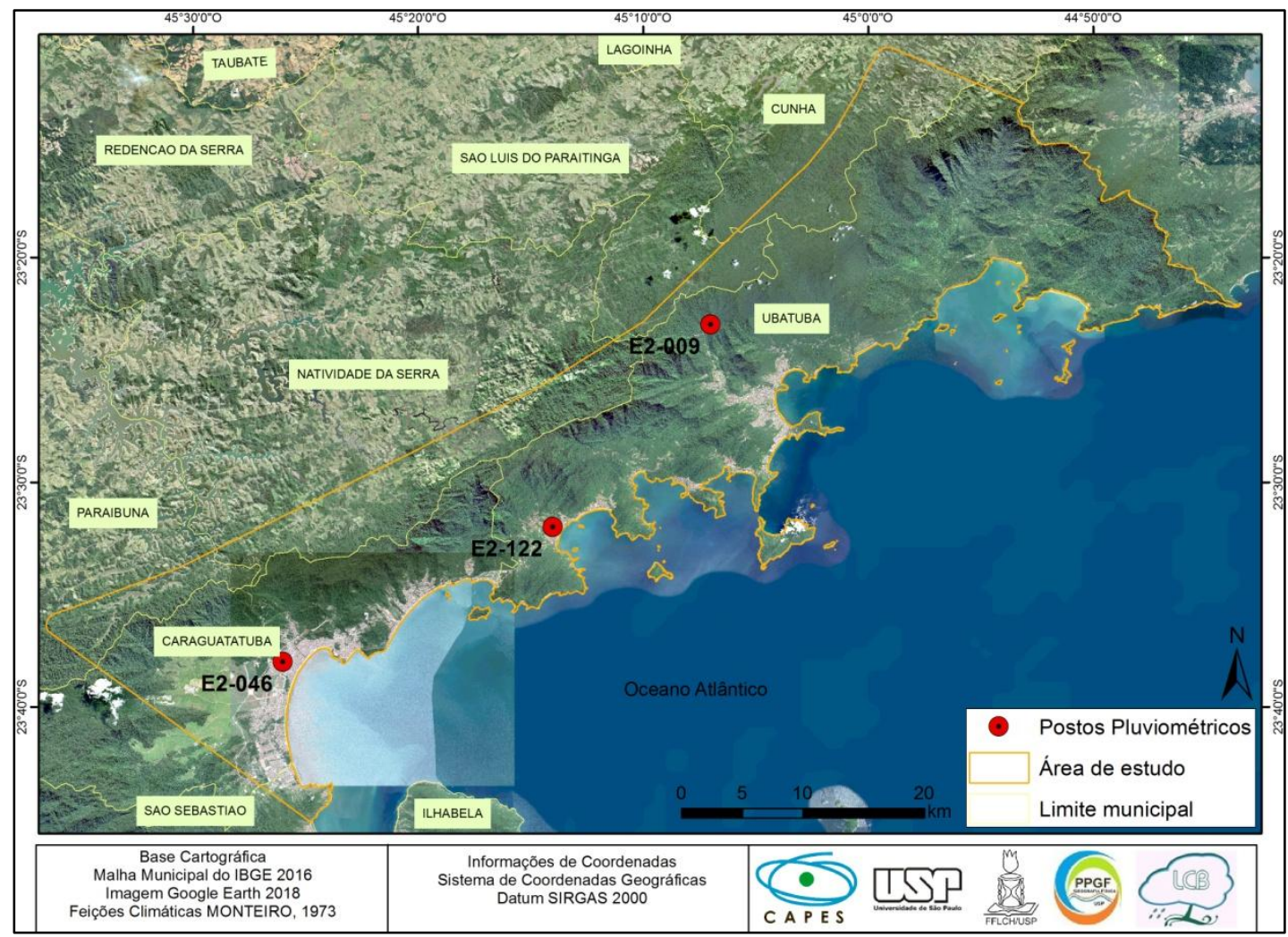

Figura 3 - Localização dos postos pluviométricos na área de estudo.

Tabela 2 - Localização dos postos pluviométricos da área de estudo. Fonte: DAEE.

\begin{tabular}{lccccc} 
Prefixo & Período & Nome do Posto & $\begin{array}{c}\text { Altitude } \\
\mathbf{( m )}\end{array}$ & Latitude & Longitude \\
\hline E2-046 & $1943-2014$ & CARAGUATATUBA & 20,0 & $23^{\circ} 38^{\prime} 00^{\prime \prime}$ & $45^{\circ} 26^{\prime} 00^{\prime \prime}$ \\
\hline E2-009 & $1956-2016$ & MATO DENTRO & 220,0 & $23^{\circ} 23^{\prime} 00^{\prime \prime}$ & $45^{\circ} 07^{\prime} 00^{\prime \prime}$ \\
\hline E2-122 & $1970-2001$ & MARANDUBA & 4,0 & $23^{\circ} 32^{\prime} 00^{\prime \prime}$ & $45^{\circ} 14^{\prime} 00^{\prime \prime}$ \\
\hline
\end{tabular}

\subsection{DEFINIÇÃO DOS EVENTOS EXTREMOS}

Para Dunlop (2008) um evento extremo é "um termo usado em climatologia para os maiores ou menores valores de um parâmetro meteorológico específico para o período em análise" (DUNLOP, 2008, p.83). Por exemplo, nas cidades de Crato, Fortaleza e Sobral, Monteiro e Zanella (2017) definiram, com base na literatura, o limiar de $50 \mathrm{~mm}$ em 24 horas para a ocorrência de eventos extremos. Contudo, não houve ponderação no fato que os 
limiares, adequados estatisticamente, não consideram as especificidades de cada localidade.

Para definir o limiar de ocorrência dos eventos extremos de precipitação, utilizou-se a técnica do Box Plot, que é amplamente empregada para a definição de alguns parâmetros de estatística descritiva como valor máximo e valor mínimo, mediana, quartis e outliers (GALVANI; LUCHIARI, 2012). Neste estudo, para o box os procedimentos envolveram a definição de percentis, a saber: base inferior na ordem de 5\% dos dados; base superior na ordem de $95 \%$ dos dados. Os whiskers (prolongamentos do box) se estendem até o limiar definido para os eventos extremos inferiores e superiores.

$\mathrm{Na}$ elaboração dos gráficos de Box Plot os dados diários foram estruturados em ordem crescente; considerou-se apenas os dias com chuva, cuja precipitação foi igual ou superior a $1 \mathrm{~mm}$ em 24 horas, de acordo com a recomendação a Organização Meteorológica Mundial (OMM), aplicada por Ramos et al. (2009) e Espírito Santo e Satyamurty (2002). Estabeleceram-se os quantis (percentis) de ordem $1 \%$ a $99 \%$, ou seja, valores inclusos nestes intervalos são considerados habituais. Os quantis "são medidas de separação para distribuições de probabilidade ou para suas amostras. Um quantil de ordem $p$ (definido para $0<p<1$ ) é um valor numérico que secciona a distribuição em duas partes, com probabilidades $p$ (à esquerda deste quantil 'teórico') e 1-p (à direita)." (XAVIER; XAVIER; ALVES, 2007, p.3). As precipitações cujos valores extrapolam os $99 \%$ do conjunto de dados foram consideradas eventos extremos.

Para avaliar a ocorrência de eventos extremos em relação ao tempo (em anos), utilizou-se o coeficiente de correlação ( $r$ ) definido por Crespo (2002): fraco $(0,0$ a 0,3$)$, moderado $(0,3$ a 0,6$)$ e forte (maior que 0,7$)$. A correlação é nula quando tem o valor de zero; quanto mais próxima dos valores de 1 (correlação positiva) ou -1 (correlação negativa), mais exata é a correlação as variáveis (tempo e eventos extremos, para este caso).

\section{RESULTADOS E DISCUSSÃO}

A tabela 3 apresenta dados estatísticos dos postos pluviométricos extraídos das análises de Box Plot. Os valores máximos de precipitação diária ultrapassaram os $200,0 \mathrm{~mm}$ em todos os postos e, particularmente, no posto E2-009 atingiu o valor máximo de 500,0 mm; a hipótese aceita para este valor é que ocorreu o transbordamento do pluviômetro o que possivelmente inviabilizou o registro de valores acima do suportado pelo equipamento. Para a construção dos gráficos de Box Plot, foram delimitados os percentis; a partir deles encontraram-se os limiares de valores extremos de precipitação diária.

Tabela 3 - Dados estatísticos gerados a partir do Box Plot. Valores em mm.

\begin{tabular}{cccccccc}
\hline Posto & $\begin{array}{c}\text { Dias com } \\
\text { chuva }\end{array}$ & Mediana & Min & Máx & $\begin{array}{c}\mathbf{1}^{\mathbf{0}} \\
\text { quartil }\end{array}$ & $\begin{array}{c}\mathbf{3 0}^{\mathbf{0}} \\
\text { quartil }\end{array}$ & $\begin{array}{c}\text { Extremos } \\
\mathbf{Q ( 0 , 9 9 )}\end{array}$ \\
\hline E2-046 & 9381 & 13,2 & 1,0 & 240,8 & 3,2 & 16,7 & 80,9 \\
\hline E2-009 & 8916 & 18,6 & 1,0 & 500,0 & 3,7 & 22,0 & 134,2 \\
\hline E2-122 & 3423 & 17,9 & 1,0 & 410,0 & 4,5 & 22,6 & 111,5 \\
\hline
\end{tabular}


Ao realizar a correspondência entre eventos extremos de precipitação e notícias históricas de jornais em Belém (PA), Campos, Mota e Santos (2015) aplicaram a técnica dos quantis, baseado em Xavier et at. (2007). Os autores definiram decis $(10 \%, 20 \% . . .90 \%)$ para os dados de precipitação diária, de modo que o nono decil corresponde à ocorrência dos eventos extremos. Para a referida área de estudo, foi definido que um evento extremo ocorre quando a precipitação diária é superior a $24 \mathrm{~mm}$ em 24 horas.

Oliveira e Galvani (2017), no perfil Paraty (RJ) - Campos do Jordão (SP), empregam a técnica estatística dos gráficos Box Plot, que classifica a série de dados pluviométricos em quantis, onde os outliers representam os valores extremos. Segundo os autores, as séries históricas apresentaram muitos dias com chuvas menos intensas, porém os eventos extremos existentes devem ser considerados devido sua intensidade. No estudo, as análises via Box Plot foram importantes, pois esta técnica gera resultados detalhados, permitindo um melhor conhecimento da variabilidade pluviométrica da área de estudo.

O Box Plot para o posto E2-046 definiu o limiar de $80,9 \mathrm{~mm} /$ dia para a ocorrência de extremos (figura 4), os percentis de $5 \%$ a $95 \%$ das precipitações ficaram entre $1,3 \mathrm{~mm}$ e $43,4 \mathrm{~mm}$ e foram contabilizados 93 eventos no período de 1943 a 2014. Destes, 66 ocorreram no verão, 7 na primavera, 18 no outono e 2 no inverno. A maior ocorrência de eventos durante o outono, se comparado à primavera, pode ser justificada pela passagem de frentes frias na região. Apesar da tendência de diminuição das chuvas nesta estação, os sistemas frontais são os principais responsáveis pelas precipitações. A velocidade do deslocamento de um sistema é importante para definir a quantidade e intensidade da chuva: quanto mais lento, maior a probabilidade de ocorrência de um evento extremo (DOSWELL et al.,1996).

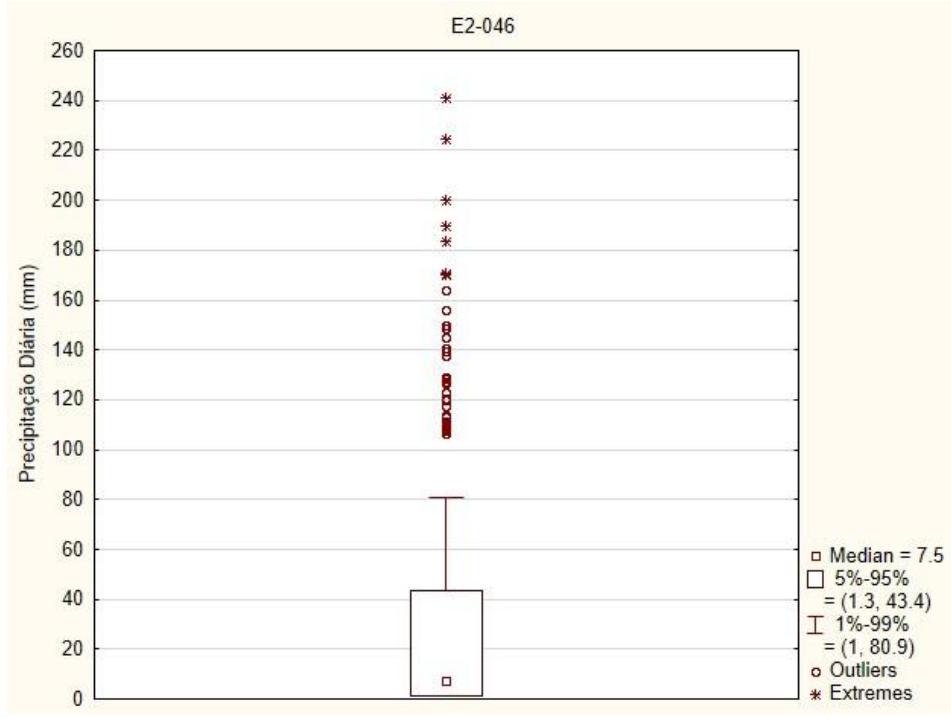

Figura 4 - Box Plot para o posto E2-046.

A figura 5 ilustra o Box Plot produzido com os dados do posto E2-009. Os percentis estiveram entre $1,3 \mathrm{~mm}$ e $66,2 \mathrm{~mm}$. Foram identificados 89 eventos extremos no período de 1956 a 2016 (60 anos), sendo esta a segunda maior série histórica do estudo; 43 eventos foram registrados no verão, 22 no outono, 20 durante a primavera e 4 no inverno. 


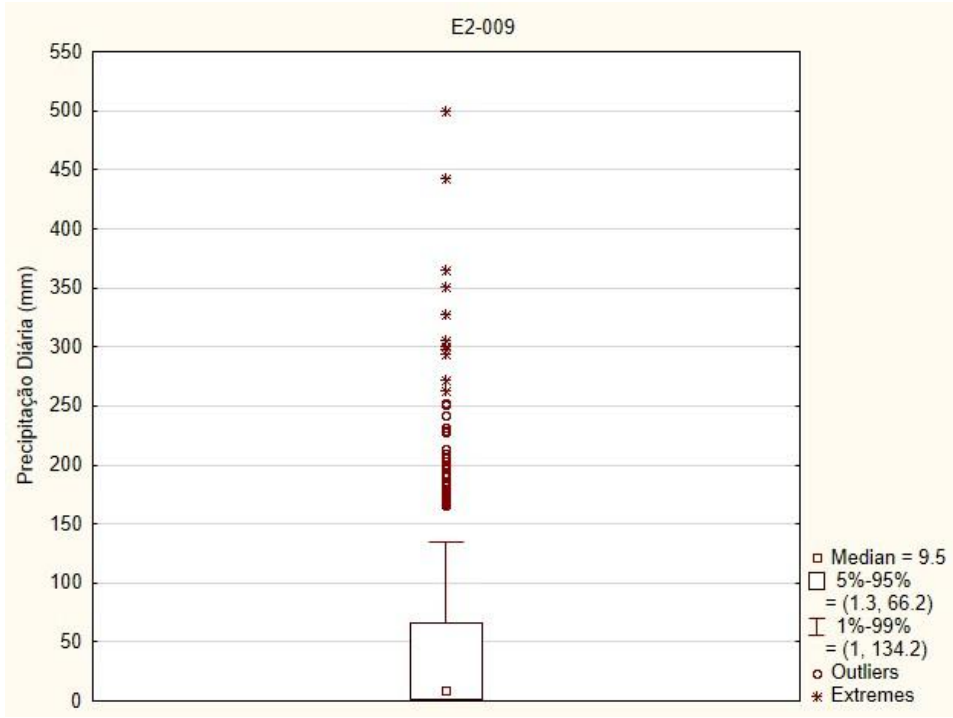

Figura 5 - Box Plot para o posto E2-009.

Por fim, o posto E2-122 apresentou o registro de 34 eventos extremos no período de 1970 a 2001. O limiar definido foi de $111,5 \mathrm{~mm}$ de precipitação diária, com percentis de $1,5 \mathrm{~mm}$ a $56,3 \mathrm{~mm}$, conforme mostra a figura 6 . Identificou-se a ocorrência de 21 eventos no verão, 7 no outono, 5 na primavera e 1 no inverno.

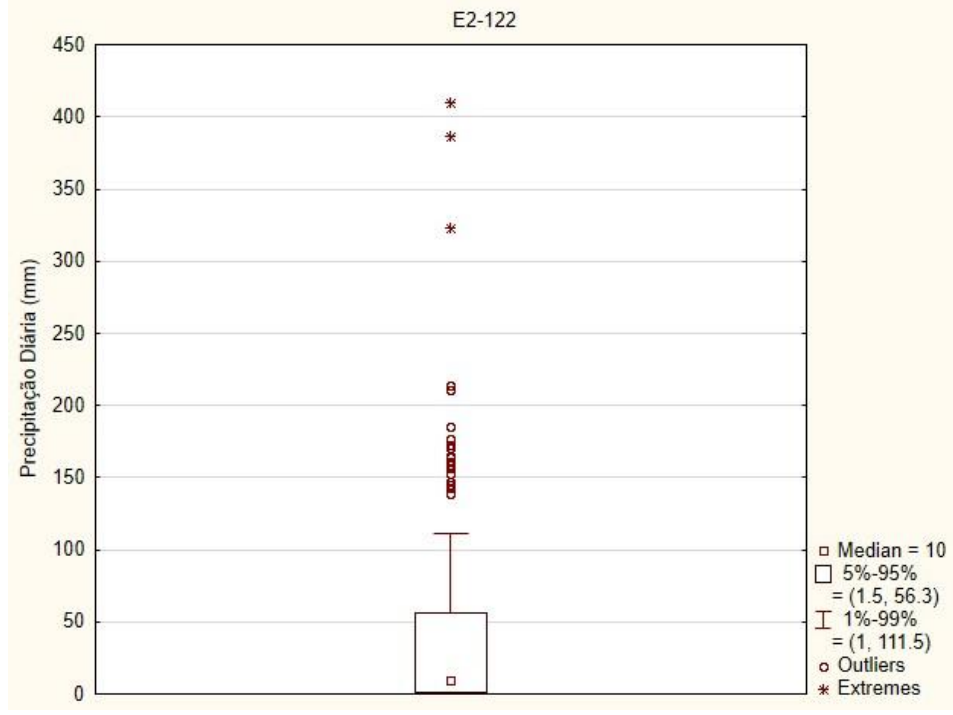

Figura 6 - Box Plot para o posto E2-122.

Para o estado de Minas Gerais, Reis et al. (2018) trabalharam com o percentil de 5 a 95\% para estabelecer os eventos de precipitação extrema no período seco (abril a setembro) e período chuvoso (outubro a março). Os limiares para definição dos extremos na estação chuvosa apresentaram valores entre $36,0 \mathrm{~mm}$ e $55,0 \mathrm{~mm}$ e, na estação seca, valores entre $18,0 \mathrm{~mm}$ e 47,0 $\mathrm{mm}$, sendo que nos meses de inverno estes limiares são mais baixos. Assim como no LNP, os eventos extremos de precipitação em Minas Gerais ocorrem com maior frequência na estação chuvosa, porém neste estado há 
predominância dos eventos durante o mês de dezembro, seguido pelo mês de janeiro.

Santos e Galvani (2014), ao realizar um trabalho sobre a distribuição horária e sazonal das precipitações em Caraguatatuba, definem faixas de frequências de precipitações, para a determinação dos eventos extremos ocorridos na área de estudo no período de 2007 a 2011. Os autores consideram "extremos" os eventos diários acima de $40 \mathrm{~mm}$. As análises registraram nove eventos, sendo que destes, seis ocorreram durante o fim da tarde e início da noite, no período mais chuvoso (verão e primavera), onde há a influência da convecção térmica (aquecimento do oceano) e do relevo. Durante o outono e o inverno, as chuvas são condicionadas à passagem de sistemas frontais e podem ocorrer em qualquer horário do dia.

As figuras 7 a 9 apresentam o número de eventos extremos ocorridos por ano nos postos E2-046, E2-009 e E2-052, respectivamente. Em uma série histórica de 71 anos, o posto E2-046 registrou 93 eventos; o posto E2-009, com 60 anos de dados, registrou 89 eventos e o posto E2-122 registrou 34 eventos em 31 anos de registros pluviométricos. O maior número de eventos no posto E2-046 pode ser justificado pelo número de anos da série (é a mais longa no comparativo); já para o posto E2-009, além disso, há o fato da localização geográfica do posto, na vertente oceânica da Serra do Mar, a 220 metros de altitude. Nesta localidade há a influência da orografia na formação das precipitações diárias. Com a menor série histórica, o posto E2-122 também possui o menor número de eventos extremos registrados.

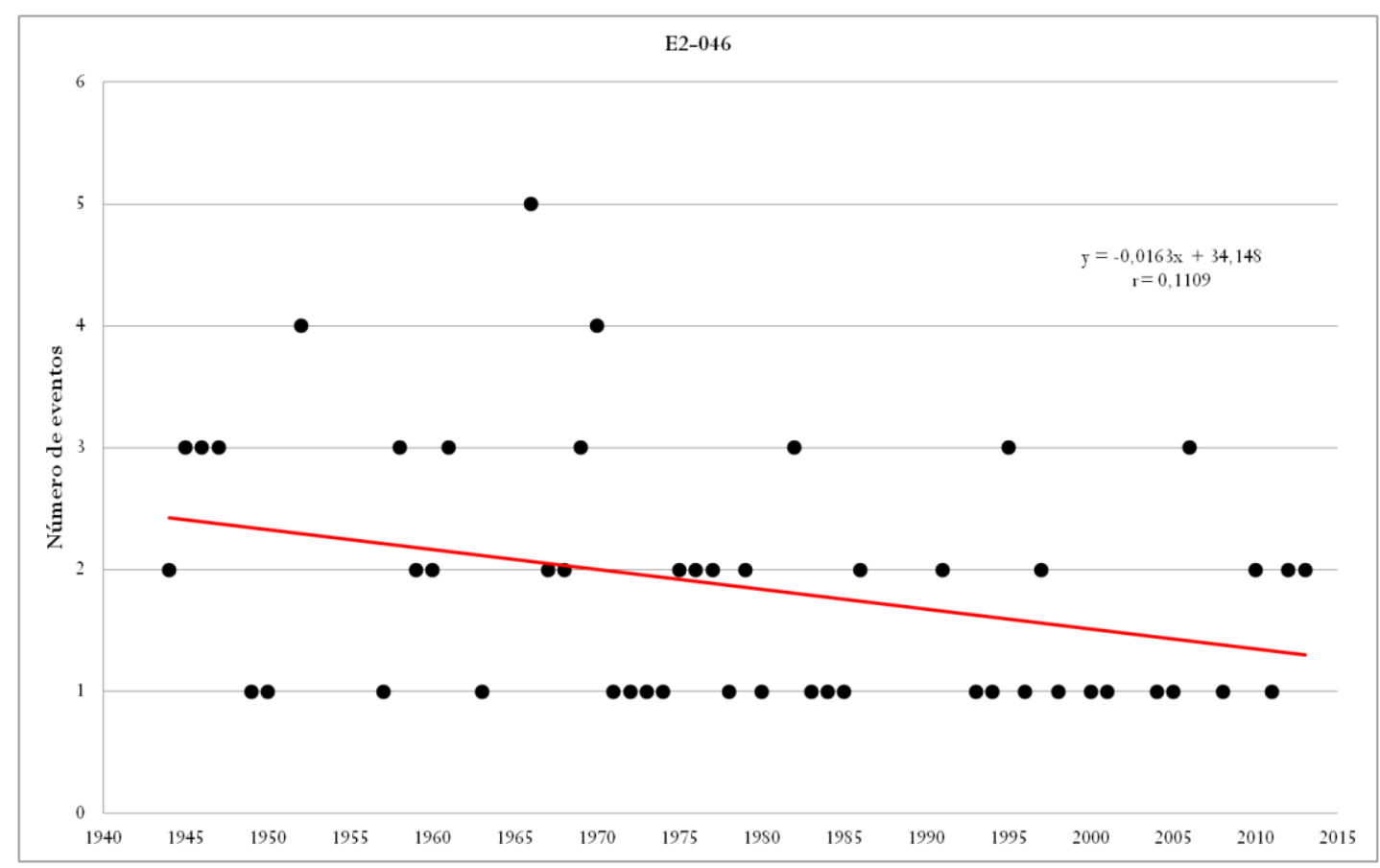

Figura 7 - Número de eventos extremos por ano no posto E2-046. 


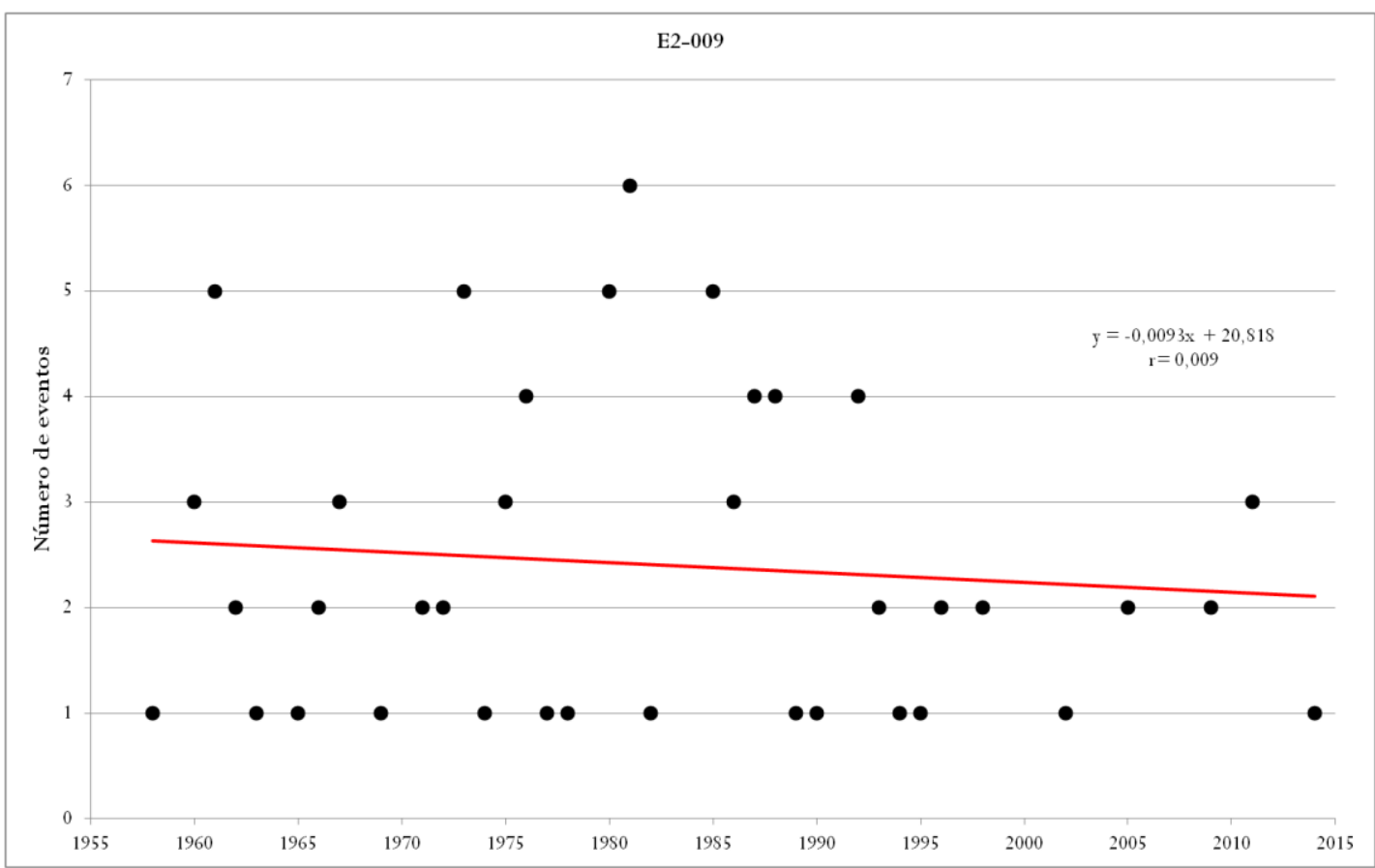

Figura 8 - Número de eventos extremos por ano no posto E2-009.

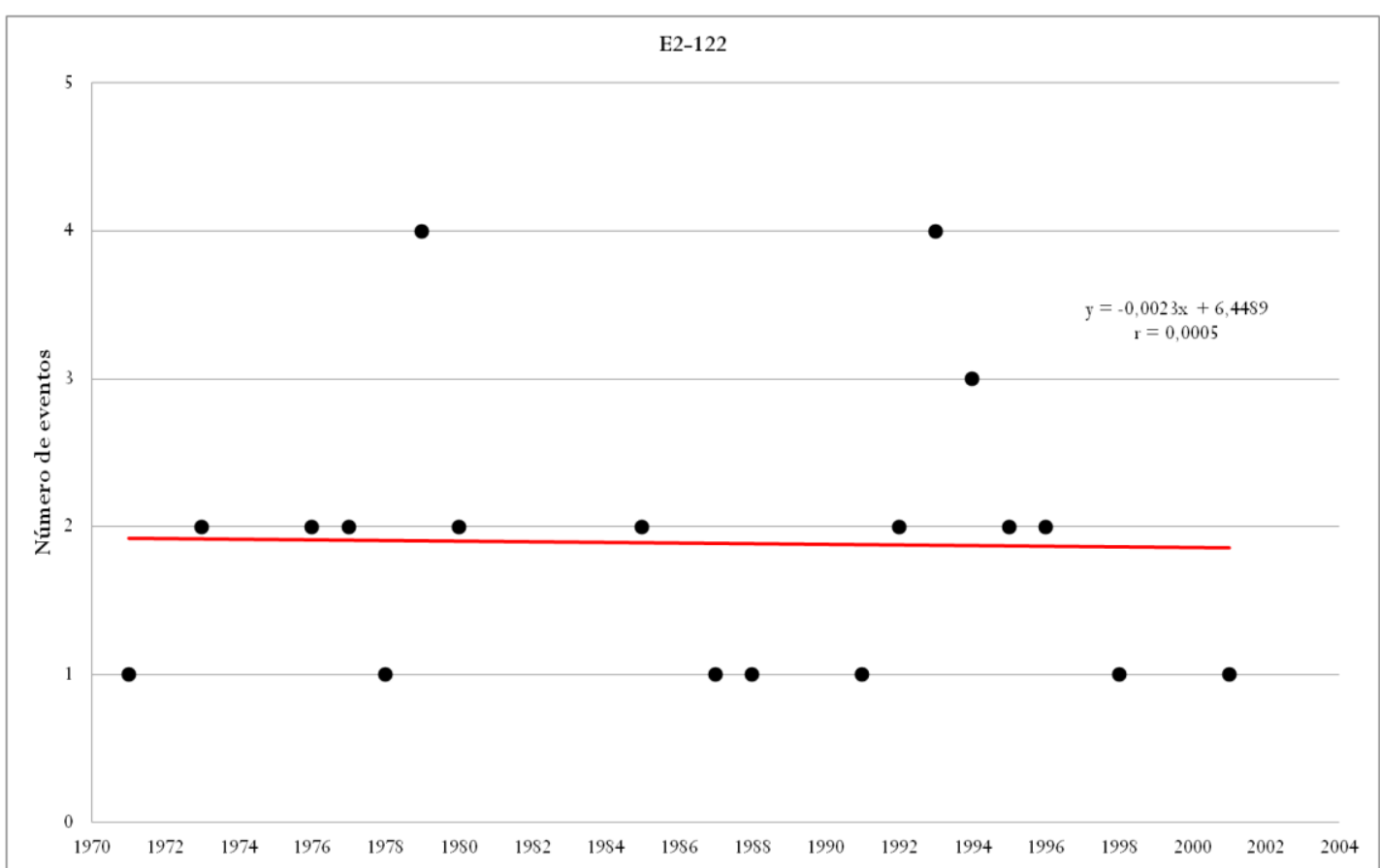

Figura 9 - Número de eventos extremos por ano no posto E2-122.

Calculou-se o coeficiente de correlação ( $r$ ) para verificação da existência da relação dos eventos extremos com o tempo (em anos). Para todos os postos o índice $r$ foi classificado como fraco, sendo que para os postos E2-009 e E2122, a correlação pode ser considerada como nula dada a proximidade com o valor de zero. Na análise visual há a diminuição dos eventos extremos de acordo 
com a reta de ajuste, contudo os valores não são significativos estatisticamente (tabela 4).

Tabela 4 - Coeficientes de correlação entre eventos extremos e o tempo (anos).

\begin{tabular}{cc}
\hline Posto & Coeficiente de correlação (r) \\
\hline$E 2-046$ & 0,1109 \\
\hline$E 2-009$ & 0,0090 \\
\hline$E 2-0122$ & 0,0005 \\
\hline
\end{tabular}

A distribuição mensal dos eventos extremos nos três postos mostra que, assim como a distribuição das precipitações totais, há sazonalidade na ocorrência dos mesmos (figura 10). Os eventos são predominantes nos meses de dezembro, janeiro e fevereiro (durante o verão) e diminuem a partir do mês de março (início do outono), de modo que há redução das ocorrências nos meses de inverno, inclusive com valores nulos para o mês de agosto. Armond e Sant'anna Neto (2017) também encontraram distribuição semelhante das precipitações na cidade do Rio de Janeiro, onde a ocorrência dos sistemas atmosféricos que provocam os eventos extremos atuou com maior intensidade durante a estação chuvosa.

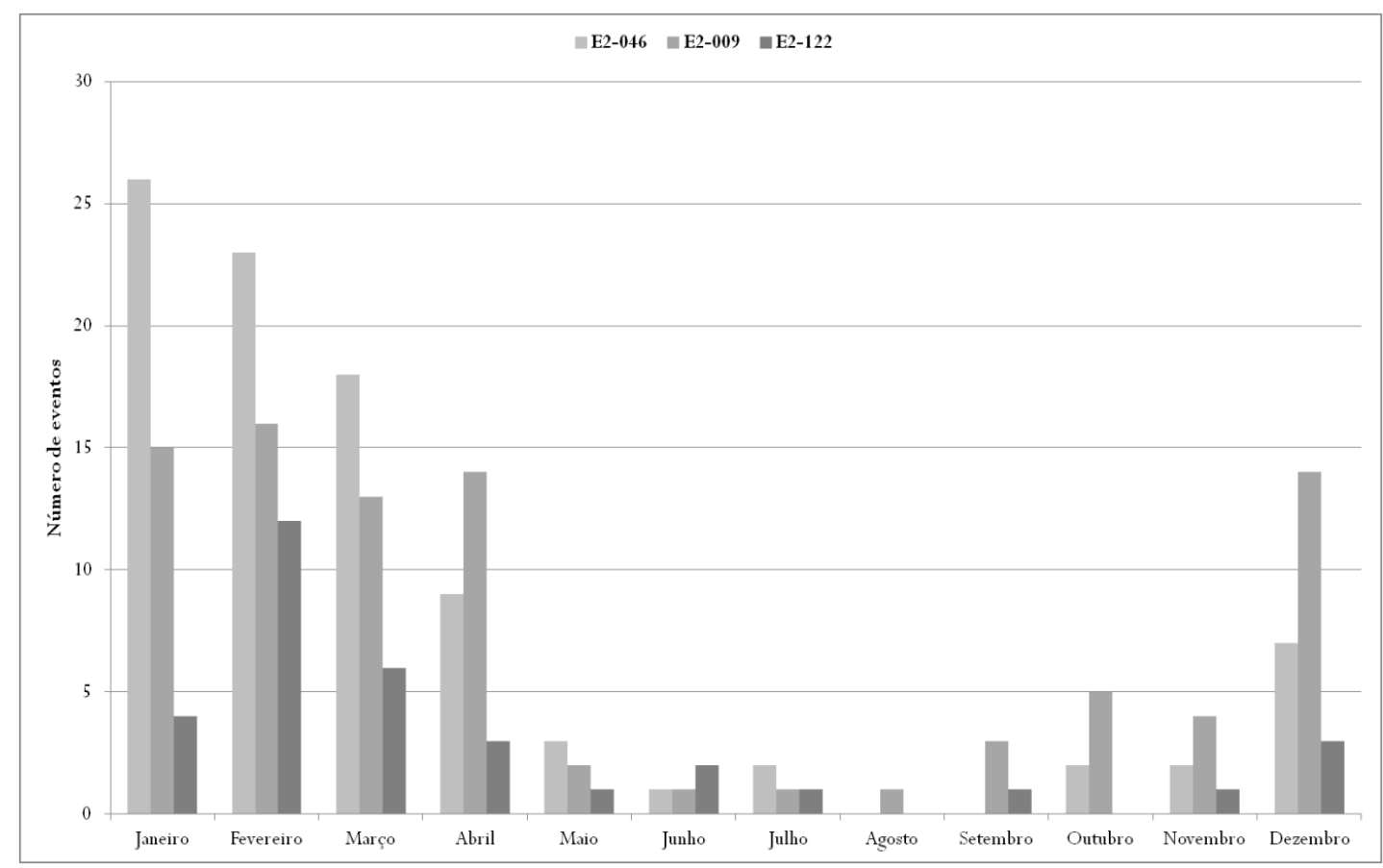

Figura 10 - Distribuição mensal dos eventos extremos (valores absolutos).

Para a cidade de Recife, Wanderley et al. (2018) aplicaram a técnica dos quantis para classificar os eventos extremos diários (quantis 0,85 e 0,95 considerados forte e extremamente forte igual a $25,1 \mathrm{~mm}$ e $50,8 \mathrm{~mm}$, respectivamente). Para os autores, a maior recorrência de eventos extremos 
entre os meses de março a agosto pode ser explicada pela atuação frequente de sistemas sinóticos convectivos, entre os quais se destacam os Distúrbios Ondulatórios de Leste e a Zona de Convergência Intertropical (ZCIT).

A comparação dos eventos extremos dos três postos pluviométricos mostra que o volume de chuva precipitado relaciona-se com a localização geográfica do posto, porém não necessariamente com a quantidade de eventos registrados, dado que os limiares são distintos para cada localidade. O posto E2009, localizado a 220 metros acima do nível do mar, apresentou o maior volume precipitado diário $(500,0 \mathrm{~mm})$, porém é no posto E2-046, cujo maior volume de chuva foi de $240,8 \mathrm{~mm}$, onde há o maior registro de eventos extremos no período.

\section{CONSIDERAÇÕES FINAIS}

A técnica estatística do Box Plot permitiu a definição dos limiares de ocorrência de eventos extremos em cada posto, dado que este tipo de análise considera a própria distribuição dos dados.

A seleção dos três postos pluviométricos (E2-046, E2-009 e E2-122) obedeceu ao critério de selecionar as séries históricas com o menor número de falhas e sua localização geográfica de acordo com a altitude. Os postos que apresentam o maior número de eventos são aqueles que possuem a série histórica mais longa, em ordem decrescente: E2-046 com 93 eventos (71 anos de dados), E2-009 com 89 eventos (60 anos de dados) e E2-122 com 34 eventos (31 anos de dados).

Os índices de correlação ( $r$ ) para todos os postos apresentaram-se fracos, sendo que para os postos E2-009 e E2-122 podem ser considerados nulos. Isto significa que há fraca (ou nula) correlação entre os eventos extremos e os anos analisados em cada posto pluviométrico.

Acompanhando a distribuição das precipitações mensais totais e médias, os eventos extremos também apresentam sazonalidade em sua ocorrência, com predominância durante a primavera e o verão. A redução dos eventos inicia-se durante os meses de outono e inverno, inclusive com ausência de eventos extremos no mês de agosto.

O estudo dos eventos extremos nos três postos permitiu concluir que a ocorrência dos mesmos depende da localização geográfica em que são realizados os registros, pois as características locais de relevo (altitude e orientação, por exemplo) influenciam no volume de chuva captado pelo pluviômetro.

\section{AGRADECIMENTOS}

O presente trabalho foi realizado com apoio da Coordenação de Aperfeiçoamento de Pessoal de Nível Superior - Brasil (CAPES) - Código de Financiamento 001.

\section{REFERÊNCIAS BIBLIOGRÁFICAS}


AB'SÁBER, A.N. Os domínios de natureza no Brasil: potencialidades paisagísticas. São Paulo: Ateliê Editorial, 2003, 159 p.

ALVAREZ, C.A.; STAPE, J.L.; SENTELHAS, P.C.; GONÇALVES, J.L. DE M.; SPAROVEK, G. 2014. Koppen's climate classification map for Brazil. Meteorologische Zeitschrift, 22: 711-728.

ARMOND, Núbia Beray; SANT'ANNA NETO, João Lima. ENTRE EVENTOS E EPISÓDIOS: RITMO CLIMÁTICO E EXCEPCIONALIDADE PARA UMA ABORDAGEM GEOGRÁFICA DO CLIMA NO MUNICÍPIO DO RIO DE JANEIRO. Revista Brasileira de Climatologia, [S.I.], v. 20, ago. 2017. ISSN 2237-8642. Disponível em: <https://revistas.ufpr.br/revistaabclima/article/view/49792>. Acesso em: 04 maio 2019. doi:http://dx.doi.org/10.5380/abclima.v20i0.49792.

CAMPOS, Thamiris Luisa de Oliveira Brandão; MOTA, Maria Aurora Santos da; SANTOS, Sergio Rodrigo Quadros dos. Eventos extremos de precipitação em Belém-PA: uma revisão de notícias históricas de jornais. Rev. Ambient. Água, Taubaté , v. 10, n. 1, p. 182-194, Mar. 2015 . Available from <http://www.scielo.br/scielo.php?script=sci_arttext\&pid=S1980993X201500010 0182\&lng=en\&nrm=iso $>$. access on $03 \quad$ May 2019. http://dx.doi.org/10.4136/ambi-agua.1433.

CENTRO DE PESQUISAS METEOROLÓGICAS E CLIMÁTICAS APLICADAS À AGRICULTURA (CEPAGRI). Clima dos municípios paulistas. Disponível em: <http://www.cpa.unicamp.br/outras-informacoes/clima-dos municipiospaulistas.html>. Acesso em 07 de setembro de 2018.

CONTI, J. B. Circulação secundária e efeito orográfico na gênese das chuvas na região lesnordeste paulista. Tese (Doutorado). Instituto de Geografia, Universidade de São Paulo, São Paulo, 1975.

CRESPO, A. A.; Estatística Fácil. 18 ed. São Paulo: Saraiva, 2002, p. 224.

CRUZ, O. A Serra do Mar e o litoral na área de Caraguatatuba: Contribuição à Geomorfologia Litorânea Tropical. Série Teses e Monografias no11, São Paulo, 1974.

DEPARTAMENTO DE ÁGUAS E ENERGIA ELÉTRICA (DAEE). Banco de dados hidrológicos. Disponível em: < http://www.hidrologia.daee.sp.gov.br/>. Acesso em 20 de junho de 2019.

DOSWELL, C. A., III; BROOKS H. E.; MADDOX R. A. Flash flood forecasting: An ingredients-based methodology. Weather and Forecasting, 11, 560-581, 1996.

DUNLOP, Storm. Definição de evento extremo. A Dictionary of Weather. : Oxford University Press, January 01, 2008. Oxford Reference. Disponível em: <http://www.oxfordreference.com/view/10.1093/acref/9780199541447.001.00 01/acref-9780199541447-e-2465> . Acesso em 02 de maio de 2019.

EMPRESA PAULISTA DE PLANEJAMENTO METROPOLITANO S/A (EMPLASA). Região Metropolitana do Vale do Paraíba e Litoral Norte: sobre a RMVPLN. Disponível em: <https://www.emplasa.sp.gov.br/RMVPLN>. Acesso em 07 de setembro de 2018.

ESPÍRITO SANTO, C. M.; SATYAMURTY P. Eventos Extremos de Precipitação na Região Sudeste do Brasil e redondezas no período de 1997-2001. In: XII Congresso Brasileiro de Meteorologia, 2002, Foz do Iguaçu, PR. Anais do XII Congresso de Meteorologia, 2002. 
GALVANI, E. LIMA, N. G. B. As classificações pluviométricas do estado de São Paulo: uma revisão bibliográfica. In: Galvani, E; Lima, N.G.B. (org.). Climatologia aplicada: resgate aos estudos de caso. $1^{\text {a }}$ ed. Curitiba: CRV, 2012, $196 p$.

GALVANI, E. LUCHIARI, A. Critérios para a classificação de anos com regime pluviométrico normal, seco e úmido. In: Galvani, E; Lima, N.G.B. (org.). Climatologia aplicada: resgate aos estudos de caso. $1^{\text {a }}$ ed. Curitiba: CRV, 2012, $196 p$.

MILANESI, M. A. Avaliação do efeito orográfico na pluviometria de vertentes opostas da Ilha de São Sebastião (Ilhabela - SP). Dissertação (mestrado). Faculdade de Filosofia, Letras e Ciências Humanas, Universidade de São Paulo, São Paulo, 2007.

MONTEIRO, C.A.F. A dinâmica climática e as chuvas no estado de São Paulo: estudo sob a forma de atlas. Laboratório de Climatologia, Instituto de Geografia, Universidade de São Paulo, 1973, 130 p.

MONTEIRO, J. B., ZANELLA, M. E. A metodologia dos máximos de precipitação aplicada ao estudo de eventos extremos diários nos municípios de Crato, Fortaleza e Sobral-CE. Geotextos, Volume 13, Ano 13, n. 2, dez. 2017. Disponível em: < https://portalseer.ufba.br/index.php/geotextos/article/view/24011>. Acesso em 09 de maio de 2019.

PELLEGATTI, C.H.G. Avaliação espaço-temporal da precipitação no perfil da Baixada Santista - Vertentes Ocêanicas-Rebordo Interiorano da escarpa da Serra do Mar - SP. Dissertação (mestrado). Faculdade de Filosofia, Letras e Ciências Humanas, Universidade de São Paulo, São Paulo, 2007.

OLIVEIRA, M. R.; GALVANI, E. Eventos Extremos de Precipitação no Perfil Longitudinal Paraty (RJ) - Campos do Jordão (SP). Revista do Departamento de Geografia, n. spe, p. 58-66, 27 jun. 2017.

RAMOS, A. M.; SANTOS, L. A. R.; FORTES, L. T. G. Normais Climatológicas do Brasil 1961-1990 / DF: INMET, 465 p. ISBN: 978-85-62817-01-4, 2009.

REIS, André Luiz dos et al. Climatologia e eventos extremos de precipitação no estado de Minas Gerais (Climatology and extreme rainfall events in the state of Minas Gerais). Revista Brasileira de Geografia Física, [S.I.], v. 11, n. 2, p. 652660, jun. 2018. ISSN 1984-2295. Disponível em: <https://periodicos.ufpe.br/revistas/rbgfe/article/view/234146>. Acesso em: 17 jun. 2019. doi:https://doi.org/10.26848/rbgf.v11.2.p652-660.

SACRAMENTO NETO, O. B.; ESCOBAR, G. C. J. ; SILVA, P. E. D. Método objetivo para identificar episódios de Zonas de Convergência de Umidade (ZCOU) no ambiente operacional do Centro de Previsão de Tempo e Estados Climáticos CPTEC. In: XVI CONGRESSO BRASILEIRO DE METEOROLOGIA, 2010, Belém do Pará. Anais... Belém do Pará, 2010.

SANT'ANNA NETO, João Lima. DECÁLOGO DA CLIMATOLOGIA DO SUDESTE BRASILEIRO. Revista Brasileira de Climatologia, [S.I.], v. 1, dez. 2005. ISSN 2237-8642. 
SANT'ANNA NETO, J. L. Ritmo climático e a gênese das chuvas na zona costeira paulista. Dissertação (mestrado). Faculdade de Filosofia, Letras e Ciências Humanas, Universidade de São Paulo, São Paulo, 1990.

SANTOS, Denise Dias dos; GALVANI, Emerson. DISTRIBUIÇÃO SAZONAL E HORÁRIA DAS PRECIPITAÇÕES EM CARAGUATATUBA-SP E A OCORRÊNCIA DE EVENTOS EXTREMOS NOS ANOS DE 2007 A 2011. Ciência e Natura, [S.I.], v. 36, n. 2, p. 214-229, maio 2014. ISSN 2179-460X. Disponível em: <https://periodicos.ufsm.br/cienciaenatura/article/view/11891>. Acesso em: 12 nov. 2017. doi:http://dx.doi.org/10.5902/2179460X11891.

SEIXAS, Sônia Regina da Cal et al . Percepção de pescadores e maricultores sobre mudanças ambientais globais, no Litoral Norte Paulista, São Paulo, Brasil. RGCI, Lisboa, v. 14, n. 1, p. 51-64, mar. 2014. Disponível em $<$ http://www.scielo.mec.pt/scielo.php?script=sci_arttext\&pid=S1646887220140 00100005\&lng =pt\&nrm $=$ iso $>$. Acesso em 03 maio 2019. http://dx.doi.org/10.5894/rgci424.

SETZER, J. Contribuição para o Estudo do Clima do Estado de São Paulo. Separata atualizada do "Boletim D.E.R. ", IX X, XI, São Paulo, 1946. 239 p.

SILVA, A.C. O Litoral Norte do Estado de São Paulo (Formação de uma Região Periférica). Tese (doutorado). Faculdade de Filosofia, letras e Ciências Humanas, Universidade de São Paulo, São Paulo, 1975.

SILVA, A. C.; SANT'ANNA NETO, J. L.; TOMMASELLI, J. T. G.; TAVARES, R. Caracterização das chuvas no LNP. Cosmos, Presidente Prudente, v. 3, n.5, p. 39-48, 2005.

SILVA, M. E.; SILVA, C. VARIABILIDADE CLIMÁTICA - PROCESSOS FÍSICOS E DINÂMICOS NOS OCEANOS E ATMOSFERA. Revista do Departamento de Geografia, p. 372-406, 27 dez. 2012.

TITARELLI, A.H.V. A Serra do Mar. Orientação, São Paulo, v.7 , p.86-93, dez. 1986.

XAVIER, T. M. B. S.; XAVIER, A. F. S.; ALVES, J. M. B. Quantis e Eventos Extremos: aplicações em ciências da terra e ambientais. Fortaleza: RDS Editora, 2007. 278p.

WANDERLEY, Lucas Suassuna de Albuquerque et al. AS CHUVAS NA CIDADE DO RECIFE: UMA CLIMATOLOGIA DE EXTREMOS. Revista Brasileira de Climatologia, [S.I.], v. 22, fev. 2018. ISSN 2237-8642. Disponível em: <https://revistas.ufpr.br/revistaabclima/article/view/56034>. Acesso em: 04 maio 2019. doi:http://dx.doi.org/10.5380/abclima.v22i0.56034. 